\title{
Jóvenes y creatividad: entre futuros sombrios y tiempos de conquista. José Machado Pais. Barcelona: NED Ediciones, 2020
}

\author{
Mariano Urraco Solanilla \\ Universidad a Distancia de Madrid, España. \\ mariano.urraco@udima.es
}

Antes de que la opinión pública fuera una vez más exhortada a dirigir su mirada reprobatoria a los jóvenes, recurrente chivo expiatorio de fracasos sociales y políticos, se publicó, en abril de este año 2020, Jóvenes y creatividad, traducción del original Juventude $e$ criatividade, que reúne un conjunto de cinco trabajos del investigador portugués José Machado Pais. Este libro recopilatorio, integrado en la Biblioteca de Infancia y Juventud que NED Ediciones desarrolla desde hace unos años bajo la dirección de Carles Feixa (prologuista y a la sazón editor de esta obra), recibe el subtítulo de Entre futuros sombríos y tiempos de conquista, difícilmente más actual en nuestros días. Machado, profundo conocedor de la obra de los clásicos, abre la Introducción a esta compilación citando a Mannheim, quien expusiera, en su Diagnóstico de nuestro tiempo (1944 [1943]), el papel que la juventud puede jugar en la revitalización de la sociedad y en el descubrimiento de nuevos rumbos sociales en tiempos de crisis. Así sucedió en los sesenta, asi sucedió tras la crisis de 2008, y así volverá a ser en el incierto panorama de nuestra época, exigiendo una nueva respuesta a la juventud (o a "los jóvenes", en plural, como se ha traducido en este libro). "¿De qué estará hecho el mañana de los jóvenes de hoy?", se pregunta Machado, citando a Víctor Hugo, para dar título al último de los capítulos incluidos en este volumen, y se dibujan los perfiles de un nuevo tipo humano alumbrado por el escenario marcado por la pandemia de COVID-19, hito o acontecimiento crucial que podría dar origen a una generación (efectiva, no solo potencial, real más allá de las etiquetas) que, partiendo de la socialización en una pauta biográfica todavía idealmente lineal, habrá de adoptar el rizoma y el laberinto como horizontes biográficos, contando con la creatividad, en el sentido amplio del término en que lo maneja el sociólogo portugués, como mínima brújula para moverse, afanosamente, en el nuevo contexto socioeconómico del que estará hecha la tercera década del siglo XXI. La noción de generación, tan cara a Mannheim y tan presente en el análisis de los juvenólogos como Machado, vuelve a estar en el debate.

Constituye este libro una aproximación, necesariamente limitada, a la obra de un autor tremendamente prolífico (por más que relativamente poco traducido al castellano). Desde esa perspectiva, la recopilación resulta un tanto escueta para dar cuenta de la riqueza del enfoque de Machado, si bien permite al lector entrar en contacto con la manera de hacer Sociología, tan personal, de este autor, que utiliza con gran acierto la propia experiencia cotidiana para leer y analizar la sociedad que nos rodea, en un ejercicio de extrañamiento que está en la mejor tradición etnográfica de algunos de nuestros clásicos. Así, múltiples son las voces que integra Machado en su mirada sobre la realidad del mundo social, mirada incansable y siempre dispuesta a captar matices y a dejar sorprenderse (a aprender y a aprehender de la interacción con los demás, con ese Otro tantas veces difuminado en análisis sociológicos menos ricos). En los estudios que componen este libro encontramos, así, múltiples fuentes, que van desde finas lecturas de los clásicos de la Sociología hasta 
la minuciosa atención puesta sobre elementos de la cultura pop, como composiciones de raperos o grafitis pintados en los muros de las ciudades, elementos que, como una escueta conversación con un vagabundo ucraniano o como el encuentro casual con una poetisa en paro, llevan a Machado a formular interpretaciones y a dibujar las formas y los contornos de la sociedad y, en particular, de los jóvenes que se mueven dentro de ella. No faltan, por supuesto, referencias más doctas o eruditas, aprovechadas siempre con acierto por Machado, que hace de la metáfora una herramienta útil para vincular, por ejemplo, los movimientos de los skaters patinando en un parque o las historias de vida de unos dibujantes de cómic con el pensamiento de Santo Tomás de Aquino, Simmel, Foucault o Deleuze y Guattari. El detalle con el que el autor portugués cuida el lenguaje (muy bien respetado en las traducciones que incorpora este volumen), los juegos de palabras y el interés en rastrear la etimología de los términos enfatizan la idea del carácter dialógico del mundo social, de su construcción permanente en lo cotidiano. La de Machado, como él mismo apunta en el prólogo conversacional de esta obra, en el que le explica a Carles Feixa cómo surgió su interés por la Sociología a partir de su experiencia como músico popular, es una perspectiva deliberadamente flâneur, pero, sobre todo, tremendamente vívida, que serviría para acercar la Sociología a la vida cotidiana (y viceversa). Los textos de Machado, como ya se viera en esa opera prima (en cuanto a traducción al castellano) que fue Chollos, chapuzas, changas (2007 [2001]), mezclan la experiencia personal (casi a modo de diario) con el análisis sociológico o, mejor dicho, hacen de la experiencia personal objeto de dicho análisis, en lo que no deja de ser una declaración de intenciones: el investigador, y seguramente más todavía el juvenólogo, no puede desligarse de la realidad investigada.

El libro se abre, como se ha señalado, con un prólogo en el que el sociólogo portugués conversa con el profesor Feixa sobre el origen de su vocación y sobre el propio contenido que se recoge en los distintos capítulos de esta obra, contenido que es revisado y presentado, a continuación, en la Introducción firmada por el propio Machado. Como se ha apuntado anteriormente, esta obra está compuesta por una serie de trabajos publicados previamente, bien sean artículos que vieron la luz en portugués, como el que constituye el capítulo 1 (publicado en 2012 en la revista Estudos Avançados), o bien se trate de capítulos recogidos en obras todavía no traducidas al castellano (como los textos de los capítulos 2 y 4, procedentes de Nos rastos da solidão -2006- y de Criatividade, Juventude e Novos Horizontes Profissionais -2012-, respectivamente). El capítulo 3, por su parte, sí que apareció originalmente en castellano, formando parte del libro Los jóvenes y el futuro: procesos de inclusión social y patrones de vulnerabilidad en un mundo globalizado, compilado por Bendit, Hahn y Miranda en 2008). Por último, el capítulo 5, que cierra este libro que se reseña aquí, sería el único material inédito hasta la fecha, elaborado a partir de una serie de intervenciones que Machado ha realizado en los últimos años, incluyendo su participación en las II Jornadas de Investigación de Estudios sobre Juventud, organizadas en noviembre de 2017 por el Centro Reina Sofía sobre Adolescencia y Juventud y la Red de Estudios de Juventud y Sociedad.

El hecho de que esta obra recoja trabajos que abarcan un espacio temporal (y social) de más de una década dota a la lectura de una cierta posibilidad de diálogo entre unos capítulos y otros, siempre moviéndose en torno al eje narrativo del papel que desempeña el elemento de la creatividad en la manera en que los jóvenes se enfrentan al mundo. Este componente agonístico queda patente en la reflexión que se propone en el primer capítulo, que iría en la línea de trabajos previos de Machado (2007 [2001], 2002) al plantear la situación de incertidumbre que experimentan los jóvenes en el contexto de la (pen) última crisis económica, que da origen a "generaciones que no creen en el futuro o que lo temen" (p. 31), a juventudes frustradas por la falta de correspondencia (o "disritmia", siguiendo a Barthes) entre los marcadores sociales de cambio de fases de vida (el esquema lineal y secuencial de transición a la vida adulta) y la realidad azarosa de los cursos de 
vida marcados por la imprevisibilidad y la falta de certezas, es decir, el contraste entre los topos que idealmente se han de ocupar y los tropos (desvíos, "tumbos") biográficos, que amenazan con generar una falta de confianza en el futuro, un "déficit de esperanza" (p. 33) entre estos jóvenes, lo que en ocasiones les puede llevar a desarrollar fórmulas escapistas de exacerbación de un presente que se intenta asir ante lo vaporoso que resulta el futuro, tan saturado de expectativas como carente de seguridades.

Y es precisamente esa sensación de extrañeza hacia un futuro que se considera lejano y por momentos hostil lo que da sentido al enlace con el segundo de los textos recogidos en el volumen, compuesto, a su vez, a la manera de Machado, por varios retazos que se van hilando en una única narración en la que las instantáneas nos llevan de un aeropuerto lisboeta a Rumanía y de vuelta a Portugal para, a la vez, llevarnos del tiempo de la tradición al de la posmodernidad, cada uno atravesado por pautas de interrelación social bien diferenciadas y, en ocasiones, contradictorias en su coexistencia. La mirada de la joven inmigrante rumana sobre la sociedad portuguesa sirve como herramienta metafórica para analizar la condición de extranjero (o de "forastero" o "extraño", siguiendo a Schütz -1944- como hace Machado) que ocupan los jóvenes en la vida social, reforzada en el caso de aquellos que deben integrar en su personalidad "matrices culturales" diferentes a las suyas originarias.

Será este proceso de integración y de adaptación, de cierto encaje entre las diferencias, lo que permita al editor conectar este texto con el que se ofrece en el capítulo 3, toda vez que alli se parte de la reivindicación de un "derecho a la diferencia" como rasgo característico de los jóvenes y como punto de fricción destacado en la relación de estos con las formas políticas tradicionales. En este punto, Machado, a partir del afán por la diferencia y el reconocimiento de la diversidad, destaca una definición "juvenil" de ciudadanía, que debiera dejar de ser vista como un sistema de encuadramiento, cerrado, para dar entrada a una mirada más abierta, de una ciudadanía en construcción permanente, más allá de rígidos ordenamientos y estructuras solidificadas. En uno de sus giros habituales, el autor portugués se sirve de la referencia a un videojuego (SimCity) y a la observación de un grupo de skaters para apostar por una ciudadanía participada, fluida y empática, en lugar de una abstracta y estática. La fluidez, como elemento propio de muchas culturas juveniles, lleva a plantear una ciudadanía "trayectiva" (Virilio, 1997), que va más allá de lo "objetivo" y de lo "subjetivo", centrándose en los contactos, las aproximaciones, las derivas.

La fluidez o la deriva, que ya han sido destacadas por Machado en otros trabajos, son aspectos explotados nuevamente en el estudio recogido en el capítulo 4 de este libro, en el que se analiza, a partir de los relatos de varios dibujantes de cómic portugueses, el doble proceso de profesionalización de la creatividad y/o de creativización de las profesiones u ocupaciones laborales de estos jóvenes, tomados como muestra de conveniencia de toda una generación. El cómic, ahora, aparece en el análisis del investigador portugués como una suerte de representación de la propia vida de los jóvenes contemporáneos, enfrentando la natural linealidad de la narración con las discontinuidades, movimientos de reversibilidad o puntos de inflexión que introducen las distintas viñetas. Como los personajes de estas historias, los propios dibujantes, en tanto que aficionados al dibujo tratando de hacer de ello su profesión, deben dominar el "arte de la pirueta" (McCloud, 1993) e ir integrando en su bagaje las distintas interconexiones que se pueden y puedan establecer entre todas las experiencias, laborales y de ocio, vitales y profesionales, que desarrollan a lo largo de su trayectoria. Puede que no se pueda "vivir del cómic" (o de cualquier otra afición o actividad), pero el cómic puede ayudar a vivir. Se trata, en definitiva, del omnipresente concepto de "competencias", que Machado, en su rica prosa, viene a subsumir bajo el recurso a la noción de "oblicuidad", concepto que toma del poeta Pessoa, como exigencia del mercado a los jóvenes contemporáneos. 
Esa oblicuidad, seguramente uno de los conceptos principales del pensamiento de Machado y, desde luego, quizás el central de los que podemos encontrar en el presente libro recopilatorio, deriva finalmente en una reflexión sobre el tiempo social y sobre la relación de los jóvenes con el pasado, el presente y el futuro. El capítulo 5, que se conecta casi a modo de respuesta con el primero, se construye a partir de una serie de mínimos ensayos en los que el autor, de partida, nos sitúa frente a la contemporánea "crisis del tiempo" (Chesneaux, 1996), que los jóvenes afrontan a partir de tres conceptos que Machado toma de Jameson (1991), a saber, la espacialización, la atemporalización y la presentificación. La evaporación del porvenir, su impredecibilidad, fomenta actitudes defensivas centradas en el presente, que se vive como estado liminal en el que el joven se atrinchera en la experiencia ante la pérdida de certezas respecto al futuro. Y es desde esa mirada sobre el presente desde donde Machado se lanza a analizar posibilidades de desarrollo futuro de la sociedad a partir de los rasgos que identifica en los jóvenes, otorgando a la tecnología (con Internet como epítome) un papel liberador destacado, como suscitadora de la comunicación entre los jóvenes y favorecedora, así, de una mayor autonomía relacional.

¿De qué estará hecho el mañana de los jóvenes de hoy?, se preguntaba Machado, y su respuesta es optimista. Entroncando con el pensamiento mannheimiano, referente, como vimos, desde la Introducción, Machado considera que los (y las) jóvenes, como generación, están dotados del valor de la creatividad, herramienta esencial para afrontar un futuro de dificultades que, por coyuntural o episódico que pueda parecer en ocasiones, hace tiempo que se instituyó como endémico para ellos y ellas en nuestra sociedad. La crisis, dice Machado siguiendo a Vigh (2008), no es una irregularidad, sino que es el contexto, la normalidad, y ello supone que la incertidumbre y la imprevisibilidad resulten consustanciales a nuestra sociedad, haciendo que la trayectoria de los jóvenes se encuentre sometida a la contingencia, a la aleatoriedad y/o al riesgo. Y, sin embargo, esa contingencia puede utilizarse como un recurso, como una oportunidad y no solo como una amenaza inevitable. "Hay que saber aprender de la crisis", había planteado Mannheim (1958 [1935], p. 21), y eventualmente explotarla, en la medida en que la actual generación potencial (la "posición generacional" -Generationslagerung- en términos de Mannheim -[1993 (1928)]-) devenga generación efectiva, en la que los principios y valores que Machado identifica en los jóvenes contemporáneos (ethos creativo, nuevas culturas laborales, solidaridad y cooperación, subjetividades sociocéntricas y cosmopolitas...) adquieran centralidad y den lugar a una reinvención social que, parafraseando el subtítulo de este libro, sirva para conquistar el futuro y hacerlo menos sombrío.

\section{REFERENCIAS}

Chesneaux, J. (1996). Habiter le temps. Passé, présent, futur: esquisse d'un dialogue politique. París: Éditions Bayard.

Jameson, F. (1991). Postmodernism, or the cultural logic of late capitalism. Durham: Duke University Press.

Machado Pais, J. (2002). Laberintos de vida: paro juvenil y rutas de salida (jóvenes portugueses). Revista de Estudios de Juventud, 56, 87-101.

Machado Pais, J. (2007 [2001]). Chollos, chapuzas, changas: jóvenes, trabajo precario y futuro. Barcelona / México: Anthropos / UAM.

Mannheim, K. (1944 [1943]). Diagnóstico de nuestro tiempo. México: FCE. 
Mannheim, K. (1958 [1935]). El hombre y la sociedad en la época de crisis. Buenos Aires: Leviatán.

Mannheim, K. (1993 [1928]). El problema de las generaciones. Revista Española de Investigaciones Sociológicas, 62, 193-242.

McCloud, S. (1993). Understanding Comics. The Invisible Art. Nueva York: Harper Collins Publishers.

Schütz, A. (1944). The Stranger: An Essay in Social Psychology. American Journal of Sociology, 49(6), 499-507.

Vigh, H. (2008). Crisis and chronicity: Anthropological Perspectives on Continuous Conflict and Decline. Ethnos, 73(1), 5-24.

Virilio, P. (1997). El cibermundo: la política de lo peor. Madrid: Cátedra.¿Qué hace una escuela como tú en tu siglo como este? Rafael Feito Alonso. Madrid: Los Libros de la Catarata, 2020 